\title{
JAAA CEU Program
}

\section{Volume 31, Number 9 (October 2020)}

The questions below refer to Manchaiah et al, "A Content Analysis of YouTube Videos Related to Hearing Aids," pages 636-645.

\section{Learner Outcomes}

Readers of this article should be able to:

- Understand the importance of online information concerning hearing health

- Recall the content as well as the understandability and actionability of information on YouTube about hearing aids

\section{CEU Questions}

1. Why do people use the internet for health information?
a. Easy access
b. Reliable information
c. No other choice

2. Actionability in the context of health information refers to:

a. The ability to comprehend and extract key information

b. The ability to identify actions that can be taken on the basis of information

c. The consideration of treatment options

3. The following tool can be used to examine the understandability and actionability of audiovisual materials:
a. DISCERN
b. PEMAT
c. PEMAT-A/V

4. What is the most frequently used method to evaluate online videos about health?
a. Popularity rating
b. Expert rating
c. PEMAT-A/V

5. The following is a popularity measure of a YouTube video:
a. URL
b. Duration of video
c. Likes

6. In YouTube videos about hearing aids, a strong relationship was observed between the following:
a. The number of views and thumbs-up
b. The number of views and thumbs-down
c. The number of thumbs-up and thumbs-down

7. YouTube videos about hearing aids most frequently contained information about the following:
a. Hearing aid type
b. Benefits of hearing aids
c. Information about hearing loss

8. In YouTube videos about hearing aids, the cost of hearing aids was most often discussed by the following:
a. Professionals
b. Consumers
c. The media

9. In terms of actionability, the hearing aid information on YouTube was found to be:
a. Inadequate
b. Adequate
c. Superior

10. Audiologists need to know the content of YouTube videos on hearing aids for the following reason:
a. To encourage patients to watch them
b. To be prepared to discuss and clarify patient concerns that may arise from watching such videos
c. To correct misinformation in YouTube videos 


\section{eAudiology}

Your CEU Source

\section{JAAA CEU PROGRAM}

WHO? All members of the Academy receive the CE Registry as a member benefit and are eligible to participate in the JAAA CEU Program.

WHAT? The JAAA CEU Program offers a minimum of 1.6 CEUs (16 continuing education hours) per volume year. Individuals can submit one or all JAAA CEU assessments for scoring and CEU credit. Each JAAA assessment is worth .2 CEUs.

WHERE? eAudiology.org-Your CEU Source

Participants can complete the assessments using the eAudiology.org online submission system, which provides automatic feedback (score, correct answers) and automatic recording to the member's CE Registry record.

WHEN? Volume 31 (2020) assessments will be accepted through December 31, 2020. Volume 31 submissions will be accepted by e-mail or online at eAudiology.org. Submissions are credited in the calendar year they are submitted. You may enroll in the CEU program for 2020 (Volume 31) with a payment of $\$ 95$ for the year. This will enable you to earn up to 1.6 CEUs for 2020.

Volume 30 (2019) assessments will be accepted for a separate registration fee of $\$ 95$ until December 31, 2020. You can earn up to 1.6 CEUs with this registration! To register, visit eAudiology.org. Volume 30 (2019) assessments will only be accepted via the online program.

WHY? Because you want convenient and cost-effective CEUs!

How? To register online, go to www.eAudiology.org. Once you have registered, the JAAA CEU Program will be added to your dashboard, and you will be able to access the assessments from there. If submitting by mail, complete the following and send with your completed answer sheet to the address below.

Education Department, JAAA American Academy of Audiology

11480 Commerce Park Drive, Suite 220 Reston, VA 20191

\section{Name}

Address

\begin{tabular}{lll}
\hline City & State & Zip Code \\
\hline Telephone & Member No.
\end{tabular}

E-mail Address

Please enroll me in the Volume 31 (2020) JAAA CEU Program. I am enclosing $\$ 95$ for the year.

I am currently enrolled in the Volume 31 (2020) JAAA CEU Program.

Please enroll me in the Volume 30 (2019) JAAA CEU Program. I am enclosing $\$ 95$ for the year. CEU Program.

I am currently enrolled in the Volume 30 (2019) JAAA

\section{TOTAL AMOUNT ENCLOSED:}

\section{METHOD OF PAYMENT:}

$\square$ Check \#

Made payable to:

American Academy of Audiology

Credit Card

$\square$ Visa

$\square$ MasterCard

$\square$ American Express

$\square$ Discover

Credit Card \#

Exp. Date 1

\section{TIER 1 CREDIT (For ABA certificants)}

$\mathrm{T} 1$

Tier 1 credit is available in this issue of JAAA. In order to receive Tier 1 credit for this assessment, you must score $80 \%$ or better. The credits will appear on your Academy transcript as Tier 1 .

$\square$ Please check here if you are seeking Tier 1 credit. 